\title{
On Growth and the Limits of Organizational Responsiveness*
}

\author{
DONALD N. MICHAEL
}

That we are assembled at this conference on Limits to Growth '75 is evidence that we are "between two ages", in Hesse's phrase: between the old myth or world view that equated improvements in the human condition with unlimited growth and the new view, far less coherent, still to be worked out, that sees both good and necessity in a world view that puts human kind back into nature, into an ecological mode of relationship with the material universe, with other humans, and with self.

In what follows I shall be contrasting the old and the new views for their implications for the limits of responsive behavior by organizations. It should be recognized, however, that the transition to a new steady-state or flow-through world is already underway in some organizations and among their constituents and consumers. Enough is happening so that my rather bald contrasts need qualifications in particular situations. But the conventional view still prevails: the dialectic between the old and new views is only now taking on depth and sophistications and the outcome is unforseeable. To a very important degree it will depend on how responsive organizations can learn to be: i.e., how open they will be to the dialectic and how much they can learn from it.

This paper will examine factors which affect the limits of effective behavior within organizations; how these may be related to commitment to unconstrained growth, and how a different belief system emphasizing a stcady state philosophy might contribute to more effective organizational behavior. ${ }^{1}$

I shall limit aspects of this complex matter examined herein to those central to my values and to the perspective of a social psychologist. My values lead me to the following observations which I have argued at length elsewhere [1].

- Organizations (for my purposes here) can and should be evaluated in terms of their responsiveness to the needs and wants of their social and natural environment and to those of their members. While there are very real limits to the

DONALD N. MICHAEL is Professor of Planning and Public Policy, School of Natural Resources, Program Director, Center for Research on Utilization of Scientific Knowledge, Inst. for Social Research, Professor of Psychology, School of Literature, Science and the Arts, University of Michigan, Ann Arbor, Michigan 48107.

*Invited Paper originally presented at "Limits to Growth "75, the First Biennial Assessment of Alternatives to Growth", The Woodlands, Texas, October 19-20, 1975. Sponsored by The Club of Rome, University of Houston, and the Mitchell Energy and Development Corporation.

(C) 1975 by Donald N. Michael. This paper will also appear in the conference proceedings, Alternatives to Growth, D. L. Meadows and R. Sweeney (Eds.), in press.

1 Unless otherwise indicated, when I refer to an "organization" I mean the people who comprise it and the rules and relationships which structure their activitics vis-a-vis that organization. 
response capability of any organization, public or private, organizations are not as responsive as they could or should be.

- The highly technologized societies are burdened by hubris; they have lost a sense of cosmic prospective and sense of interdependence with the cosmos; hence, they have lost a sense of responsibility, or responsiveness.

- A shift to an ecological, an evolutionary ethic is imperative. This in turn requires that we see ourselves as learners, as beginners, and conduct ourselves accordingly.

I hope and expect others to provide counterpositions to mine. In this way, proceeding in a Hegalian mode of inquiry, we may arrive at a more useful understanding of the relationship between alternative growth paradigms and organizational responsiveness [2]. In this regard, I should make clear at the outset that, even if the choice were made to try to operate as a society based on a steady-state, flow-through, philosophy, it might not get us out to the limits of organizational responsiveness that are engendered by performance that is consistent with belief in unlimited growth. As I shall try to show, many conditions within organizations and in the persons who perform in them, that discourage responsiveness today will have deeply burdensome equivalents in organizations operating in a more steady-state world. Most certainly the burdens would be greater during the transition period; the period of learning how to operate and to believe in a steady-state world view. However, as I shall try to show, the very fact of a new philosophy with its new values may provide new definitions of costs and benefits and a new cost/benefit balance that will be more socially and psychologically meaningful and rewarding than the old. This could encourage greater responsiveness even if the burdens of doing so are greater ... just as the technologically oriented free market philosophy with all its burdens was so refreshing and releasing for those emerging from the Feudal period.

What follows will all too briefly explore the matter in three steps:

1. What personal and structural factors limit organizational responsiveness?

2. How does the growth ethic exascerbate unresponsiveness?

3. How might a steady-state ethic increase organizational responsiveness?

In reflecting on what follows it is necessary to keep in mind that the circumstances we will review play into one another and transform into one another just as do processes in an ecological model or, as plucking one strand of a net alters the relationships of all the others and these alterations, in turn, alter the plucked strand Such is the human condition: contrary to the hopes of social scientists subscribing to the myth of Newtonian-Aristotelian reality, cause and effect are not linear nor are human being "variables" discrete and independent. One can start anywhere with these circumstances and find the others inevitably and ineluctably implicated.

\section{Personal and Structural Factors That Limit Organizational Responsiveness}

\section{PERCEIVED RESOURCE AVAILIBILITY}

Resources are perceived almost always as less than needed to do the job. But "measures" of need are always bound to the myths that define the organization's functions for its members and its constituents and the measures are always partial and incomplete. Shifting the system characteristics, reperceiving tasks, functions, goals and system boundaries shift perceptions of the "amount" of resources; that is the sense of what is needed and who needs it, 
and, hence, of sufficiency. For example, the sensed need among members for more data is a function of how data are shared or preempted in the organization. And as another example, the types of demands members of the environment make on an organization depend in part on the members' expectations about the organizations capabilities. This, in turn, is a function of the amount of their experience with the "inside" workings of the organization which, in turn, is a function of the opportunity to participate in those workings. Gencrally, more can be done with the available resources than the members of organizations are prepared to do; i.e., they are reluctant or unwilling to invent and implement the internal changes required in order to do a better job.

This is not to say that there are no financial, political, or legal limits per se but rather that, within these limits, the perception of the nature of the restraints engenders its own contribution of limits. And, of course, the financial, political, or legal constraints are subject to change partly through actions that grow from reperceptions of what constitutes appropriate responsiveness.

\section{INTERPRETIVE CONTEXT}

The policies and programs of an organization derive from the beliefs held by its members about the processes and nature of the reality to which the organization responds through its policies and programs. These beliefs and, through them, the policies and programs, form the interpretive context of the organization [3]. These beliefs may be legitimated in the form of a theory of what is "out there" and what is needed to deal with what is "out there". One way or the other the interpretive context is unavoidably selective and value-laden by virtue of what it emphasizes as important. Since the interpretive context determines what is important "out there", it also determines what is important within the organization. These two important foci interlock so as to give the members of the organization significance in their own eyes and to stabilize the relationship between organization and environment. Concomitantly, these foci also serve to delimit the range of signals both within and without the organization to which the members are expected to respond in their organizational roles. Signal and role limits and stabilization provide the very important psychological aid and comfort of familiarity and predictability. Consequently, the interpretive context serves to limit the responsiveness and innovativeness of the organization (though it can enhance the quality of the responses within its repertoire).

More specifically, the interpretive context determines what demands from the human and/or natural environment the organization will respond to: whether it responds only to routine and familiar demands or is capable of responding to the unexpected and unfamiliar; whether it responds to only a narrow range of deamnds or to a wide range; whether it can respond to conflicting demands or only to complementary demands; and whether it can deal with demands defined by anticipated futures.

That organizations see themselves and their functions from particular interpretive contexts will perhaps be more evident if one considers the ways in which organizations would respond to demands if, on the one hand, they operate in terms of economic theory based on belief in ever-expanding resources and consumption needs or, on the other hand, they operate in terms of ecological interdependence and limited resources and consumption needs. Consider, as another example, the gross differences that arise if the prevailing belief is that the highest and indeed accessible attainment of humans is fully rational behavior in contrast to the belief that humans cannot be fully rational and that their highest potential includes but is not bounded by rationality. 


\section{QUALITY OF INFORMATION}

The interpretive context strongly influences the kinds and quality of information that an organization uses to respond to its internal and external environment. This information usually reinforces the extant interpretive context but there are times it also leads to basic changes. (The most familiar example is the way anomolies in the interpretive context of science eventually lead to revolutionary changes in the paradigms that define scientific reality.) What then are some of the characteristics of the information that affect the organizations' responsiveness particularly by way of limiting it?

Is the information appropriate and sufficient for defining the response-demanding situation? For discovering alternative ways of responding? For anticipating the possible outcomes over time, especially over longer periods? Here, the absence of future studies that are in fact used (rather than merely ritually sponsored as is usually the case) becomes a crucial constraint on organizational responsiveness. Finally, is the information sought appropriate and sufficient for evaluating the responsiveness of programs and policies as they are implemented, especially in the light of anticipated outcomes as illuminated by further studies? For all of these questions circumstances are usually such that information is neither as appropriate nor as suflicient as it could be. This, because the interpretive context and the rewards for the organization, from acting consistently within that context, discourages extending or altering the interpretive context, especially in a turbulent world where new information is almost invariably upsetting to routines and expectancies and, thereby, threatening to established images of competence.

Other information considerations also tend to limit the responsiveness of organizations. The thrust in technologically advanced organizations is to emphasize and to shape information into quantitative forms. Highest credence goes to such information and high status is bestowed on the professionals producing and interpreting this information. Yet much of what is crucial about human beings, perhaps most of what is crucial, is not now expressible quantiatively and may well never be. But such is the strength of the interpretive context that emphasizes the "scientific method", the theory-myth of economic "reality", and the hardware of the computer, that the nonquantitative, the feelings and cmotions, the ineffible are either crudely mutilated-computed-into numbers, or ignored, or repressed in the name of objectivity and "facts". This limitation on information utilization holds not only regarding what information is sought from the demanding environment but, very importantly, it operates to define competent behavior among the members of the organization as that which is "objective", "rational"; i.e., data-oriented. One result is that crucial information needed for the creation and understanding of policies and programs and their implications, information in the form of the feelings and intuitions of those involved in defining and evaluating these activities, is repressed or ignored. This is at great cost, because when feelings and values are repressed, commitment to self and organization and belief in worthiness of self and organizations are lost and responsiveness thereby limited gratuitously.

A final critical limitation on the response utility of information, as it supports and is supported by the interpretive context, has to do with constraints, especially structural ones, that screen and/or preempt information among the components and subcomponents of the organization. Generally, information is seen as power. Hence the only information which tends to be sought is that which reinforces or expands the power accrued by acting in terms of a given interpretive context. And information is hoarded or traded in ways that reinforce that context for its "owners". Either way the capacity to respond to a changing situation is limited by such procedures. 
Again, this is not to say that there are not opportunity costs connected with information gathering and using. It is to say that the interpretive context serves to define and value these costs in particular ways and, usually, for reasons that are only in part "rational". Preservation of the context takes priority over changing it.

\section{PARTICIPATIVE PROCESSES}

Responsiveness is limited or augmented by the nature and degree of participative processes both among members of the organization and between members of the organization and the demanding environment. Participation provides the occasion for experience that leads to an understanding of both the needs and wants of the environment and the circumstances that affect the organization's ability to respond to these [4]. Within the organization, participation across subunit boundaries results in similar understanding with regard to the organization's components and interdependencies.

Participation is also and increasingly a necessary condition for organizational legitimacy. To the extent an organization's legitimacy is repudiated it is unable to be responsive. Often, too, its members become hostile toward its challengers-which further erodes the organization's legitimacy. Participation can result in the organization and its demander environment mutually legitimating the relationship and the responsiveness that does or will characterize it.

Participation is needed to provide information (especially nonquantative insight and understanding) and ideas and to build a risk-sharing relationship. This latter is especially important when policies and programs are innovative, even experimental, as they must be if the developing situation is likely to be dealt with constructively. The end result of effective participation is mutual influence in the direction of more effective responsiveness.

Yet, participation is generally resisted; it complicates the conduct of linearly (or hierarchically) organized activities, takes time, threatens conventional definitions of power, which rest on preemption of resources and information rather than on the sharing of them, and makes especially vulnerable the prevailing interpretive context [5]. Thus, organizations strongly tend to limit their potential responsiveness rather than seeking to discover and invent new ways of perceiving and operating that take advantage of participative norms and processes.

\section{VALUES AND MOTIVES}

Values and motives are obvious conditioners of organizational responsiveness. Nevertheless, a few observations are in order. The "facts" sought out are a function of what is valued and, as indicated earlier, what is valued is a function of the interpretive context in which one's reality is embedded. Values are in part expressed in ethical standards and affect what actions are taken and how they are carried out. Values are multiple and, operating in real human beings, in contrast to logical-philosophical exercises, they usually conflict and do not arrange themselves hierarchically. Values can be human-centered or things-centered or process-centered.

There is increasing social conflict among value priorities and more people find themselves more in conflict regarding their own values. In part this reflects the breakdown of a widely shared and workable interpretive context. It is both hopeful and complicating that self-consciousness about value conflicts, both as they exist in self and in one's organization, is in ample evidence in higher echelons of many organizations. Thus, while the organization may continue to respond in terms of older interpretive contexts, 
values, and motives, the circumstances for changes in responsiveness from this source seem potentially great.

However, increased responsiveness based on changing values and, hence, changing motives, depends in important part on the capacity to express the feelings that always underly these values and on the will and skill to translate them into goals. When goals (or means) are agreed on, as was the case when the old interpretive context was dominant, then value issues and their associated fcelings did not need to enter into consciousness or dialogue: they were implicitly agreed to in agreements on goals and means. Now, there is much less agreement, based on a shared interpretive context, so the exploration of values and feelings is a necessary condition for organizational responsiveness.

Such searching and open exploration requires far more interpersonal competence than most of us possess. In the absence of this competence the responsiveness of organizations to new demands will remain far more limited than need be.

\section{INTERPERSONAL COMPETENCE}

Among the attributes displayed by a person skilled in working effectively with others in nonroutine situations are well developed abilities to: listen to another person; express and support the expression of strong feelings; risk trusting others; seek out and acknowledge one's errors; live with and acknowledge great uncertainty; share intuitions; recognize what roles are needed in a group task and, if absent, perform them; constructively manage conflict with others, among others, and inside self; adjust well to membership changes in the social support system one has been part of; and know and understand one's deeper, extra-rational and irrational selves. Such attributes are absolutely necessary for the members of organizations that are seeking to learn to be more responsive in a turbulent world where demands from the outside, from others in the organization, and from inside oneself will increase in number, variety and unfamiliarity. For the most part such interpersonal competences can be learned and. I would arguc, must be learned if present limits on organizational responsiveness are to be reduced or kept from worsening in the face of the demands anticipated in a turbulent world.

\section{CAPACITY FOR DIFTERENTIATION AND INTEGRATION}

Responsiveness requires specialization and this results in differentiation of norms, actions, and resources into subunits operating according to appropriate functional directives. But, since such differentiated units seldom if ever have all of what is needed for a complete response to a complex demand, coordination is necessary via integrative systems. Organizations and their social environments vary in the effectiveness of their differentiation and integration. Generally speaking, the ability of an organization to respond effectively is proportionate to the degree to which its structure mirrors the structure of the demanding environment. Thus, as the environment differentiates so too in one way or another must organizations that seek to be responsive.

Tendencies toward proliferating differentiation in the environment have been encouraged by the doctrine of individualism and autonomy. They are reinforced by newly acknowledged and valued criteria for differentiation based on ethnicity, life style, and preferred value priorities, whether the differentiated entity is an alternative school, splinter professional group, or new nation. In these times the social environment tends to change its structure faster than the organizations from which it demands responses. Thus, organizations are faced with more specialized demands and thereby more need for sophisticated differentiation and integration of their specialized subunits. The ability and 
willingness of the organization to redifferentiate and reintegrate itself in order to increase or even to maintain its responsiveness depends on how the organization copes with the other factors described herein. Generally speaking, this means that organizations tend to resist remaking themselves-at cost to potential responsiveness.

\section{OVERLOAD}

Degree of overload is related to the nature of the environmental demands, the norms that define a sufficient response, the environmental reactions to a given response, and to the intraorganizational and intrapersonal reactions to the response. One way or another overload limits organizational responsiveness. Information overload occurs when there are too many data, value issues, and feelings to "fit" together in the time available. Decision-making overload occurs when the "fit" of information and the time available do not allow a satisfactory working-through of why to act, what to do, who to do it, when, and how.

Computer print outs, social indicator data, and other such "aids" are at least as likely to increase overload as to reduce it because more information increases the number of issues to be examined, options to be explored, interpretations, arguments, and ethical issues to work through. This is especially so in public organizations and it is becoming more so in private organizations as the legal and ethical obligations increase to be more responsive to both human and natural environmental denands.

Decision-making overload is also exacerbated by role conflicts resulting from imperatives generated by the conflicting values and demands differentially attached to the multiple memberships held by people in organizations: memberships in family, profession, political activities, ethnic affiliation, job, etc.

The strong tendency in heavily overloaded situations is to retreat to learned behavior successful in the past, and to narrow attention to the present [6]. Since the present is not the past, and the future even less so, malresponsiveness is typical under overload. This is not necessary and organizations can, with planning, training, and appropriate norms and reward systems, learn to be innovative under overload. While there are limits to overload responsiveness, they need not be as great as is usually the case.

\section{LEARNING CAPABILITY}

In transition periods such as ours organizations must learn to interpret their external environment differently and to define and operate their internal environment differently if their resources are to be used more responsively [7]. The capability to learn-to perceive, and act differently in response to different demands-depends on the personal characteristics of the organization's membership; upon the organization's ability to perform evaluations of both the environment and the organization, upon the organization's capacity to reorganize itself, and upon its reward system. Most organizations have primitive or nonexistent capabilities for deliberately designing and operating a learning system integrally servicing the whole organization. This is partially because we have had very little experience designing and operating such systems and partially because effective learning involves destroying conceptual, interpersonal, and operational boundaries that, while comfortable, now limit the organization's responsiveness in ways already described.

In more stable times fairly routinized relationships between organizations and their environments made organizational learning comparatively unimportant and, as such, the structures established were not directed toward or their members' rewarded for obtaining information that would engender organizations relearning about what to be responsive to 
and how. Yet, in the turbulent times ahead this social psychological and structural capability for organizational unlearning will be pivotal for effective learning for responsiveness. As it now stands, the absence of such capabilities is a crucial limitation on organizational responsiveness.

\section{REWARD SYSTEM}

Generally, organizations reward their members for their ability to: stabilize response demands and response performance through routine, co-operation. or exclusion; excell individually; maximize subunit gains; repress errors: project an image of competence; and further organizational aggrandizement efforts. New organizations reward entrepreneurship, innovation, and successful risk-taking, but as the organization ages-and this usually happens quickly-the other performance modes come to dominate. It follows that the conventional reward system strongly limits other than incremental or convenient extensions of response capability.

With this brief and oversimplified review of some important circunstances that limit the extent of organizational responsiveness to demands from inside and out, we can turn now to speculating how a continuation of the philosophy of the desirability and attainability of essentially unlimited growth can serve to further inhibit organizational responsiveness.

\section{How the Unlimited Growth Ethic Exascerbates Organizational Unresponsiveness}

Unrestrained production, assumed desirable and feasible in the belief system underlying unrestrained growth, depends on and encourages unlimited rising expectations. In turn these lead to increasing numbers of conflicting demands on organizations (a) to be responsive by producing more goods and services, and (b) to be responsive to the adverse consequences of that growth. (Production and product-produced pollution are obvious examples.) Particularly distressing and complex are the demands growing from life conditions in the third and fourth worlds since the gap between them and the first and second worlds is almost certain to continue to grow in the absence of an interpretive context premised on interdependence in a finite world. Such conflicting local and planetary denands generate more information, and require attention to more information, if organizations are to be responsive. This, of course, increases information and decision over-load and is likely to lead to comparatively less responsiveness because comparatively more information, nceded for discriminating responses, would be screened out or ignored.

The myth that production can be indefinitely increased also encourages tendencies toward splintering and the establishment of autonomous groups and activities. That is, if there need be no limits on matter and energy each dissenting group will feel encouraged to go its own way, "do its own thing", believing it can be self-sufficient and feeling little need for interdependence or to be concerned for the welfare of others. Others can "get theirs" by also tapping in to the gravy train via the time-tested means for flourishing in a capitalistic or socialistic economy.

Autonomy and differentiation, operating in and stimulated by the absence of a shared set of values and rules of conduct, will lead to continuing challenges to legitimacy; each group will be devoted to its interpretive context and to the specification of factual importance justified by its values. When integration across organizations or linkages between demanding groups and servicing organizations are needed-as surely they will, because proliferation requires linkages in a complex society and world regardless of what 
the preferred group interpretive context suggests-the need for participative involvement will increase. So, too, will the sense of the inadequacy of available resources within a given organization increase. But participation under such conditions will be frought with distrust and misunderstanding and will require much time, attention and skill, to make it productive. These requirements will prove irksome and be resisted because they interfere with the priorities that derive from an interpretive context of business/government-asusual, a viewpoint that grows out of and is sustained by belief in the desirability and feasibility of unrestrained production (see below).

The proliferation of groups and claims means that, to be appropriately responsive, an organization will be beset by a frequent requirement that it redifferentiate and find new modes of and bases for integration. This in turn will alter roles and increases role conflict as incumbents seek to discover what their new relationships are. The need for better than ordinary interpersonal competence to deal with the multiple stresses of role ambiguity, value conflict, error proneness, etc., will also increase in this setting. All this will add to information and decision overload. Consequently, responsiveness is likely to go down rather than up since internal turmoil and ambiguity will be added to that coming from outside the organization.

If unlimited growth is desirable then, in the prevailing interpretive context, technology is the major means for realizing new production and products to be consumed in the interest of more production, hence, more growth. Furthermore, again in keeping with the conventional interpretive context, whatever adverse consequences technology produces, additional technology can control. However, as Geoffrey Vickers observed some years ago, powerful technology at best increases control only over the point of first and immediate impact [8]. The more powerful it is the more widespread and various its secondary and tertiary impacts. These are essentially out of control at least until they are recognized. By then the size and consequences of the needed response usually is so great that it is strongly resisted (e.g., the resistances of many government agencies and most corporations to pollution control). Moreover, by the time one consequence has become sufficiently powerful to break through the prevailing interpretive context it may, in turn, have generated its own follow-on not yet recognized consequences. (For example, insecticidal technology led to larger populations which led to more food demands which lead to more fertilizer needs which lead to more release of nitrogen into the atmosphere which looks like it will lead to degradation of the ozone layer which leads to....) And the response to the recognized consequence itself is likely to provoke its own adverse consequences (e.g., more divisiveness between conservationists and workers who feel their jobs threatened by pollution controls).

These unanticipated consequences from unrestrained technological proliferation in the interest of more growth can only lead to contributions to social turbulence. One consequence is that organizations will be barraged with more ambiguous information. More information will be sought to make sense of what is going on, even if the reward system and interpretive context discourage seeking really new information. Much will be imposed on the organization by response claimants who also will be insisting on participation in decisions affecting their welfare (c.g., the location and construction of nuclear reactors). Both ways, the information overload goes up. But this will occur in a more encompassing context.

Greater turbulence and the persisting confrontation of unanticipated consequences from technological proliferation will batter at the public and self images of leaders and technologists (social and material) because it will become increasingly evident they don't 
really know how to regulate the processes of society in the interests of human growth and development. That is, the interpretive context that gives a feeling of reality and validity to their professional competences will become increasingly vulnerable. Two kinds of response are possible. One is to resist recognizing this. This reinforces the members' sense that they are making competent responses-by far the most typical form of behavior in crises. The other is to recognize the validity or at least the plausibility of the messages from the environment and, turning to each other for emotional and intellectual support, seek to invent ways to learn to be more responsive in the light of the evidences of professional incompetence, ignorance, and hubris. Here lie great potentials for learning that could lead to greater responsiveness. I shall return to this theme in Part III.

However, this form of response requires, among other things, high levels of interpersonal competence which in tum requires an organizational reward system that gives priority to such interdependent and searching behavior. But the values and motives that typically prevail do not reward, indeed they often punish, the practice of interpersonal competences of the sort emphasized here. Thus, the most likely reaction of organizations, whose responses increasingly or persistently demonstrate ignorance of changing reality to such degree that they cannot successfully establish or maintain their claim of competence to respond constructively to that reality, will be to block out those treats to self-image and self-confidence in ways that exacerbate their unresponsiveness.

All the response-affecting circumstances we have reviewed herein have been elaborated, in highly technologized societies, by an interpretive context (with its facets cut in the forms of economic, social, and political theory) that assumes that the "pie" can and should be made ever greater. The dominant organizations of such societies operate within this context and according to its theories (whether capitalist, communist, or socialist; liberal, or conservative). Until recently, and for the most part, this is still the context for government/corporation business and it is "business as usual". Though, obviously, there are some structural changes afoot and more changes in the values and motives of many organizational members.

Business as usual means arranging the world so as to encourage and facilitate more production and more consumption. This premise is based on the assumptions that the resources will be available, and that the capacity of the planet and its people to absorb the products and cnd-products of the productive processes is unlimited. These assumptions depend, in turn, on belief in the unlimited potential of human wants and of technology plus economic processes to meet them one way of another, and in the ability of private and public organizations to invent and control the means and the outcomes. Implicit in these beliefs in and optimism about unlimited growth is an interpretive context that says "We know how the world looks, how it adjusts itself and changes, and we know what to do to keep it working". That no one knows how to comprehend the complexities of human nature and physical nature presently interacting on this planet-this was the original premise of the Club of Rome--is not part of the interpretive context or self-image of the "business as usual" leadership at whatever level of organizational life. Nor is the reward system based on acknowledging this; quite the contrary.

Acting as if or believing that we do understand and can control, under the circumstances that characterize an increasingly turbulent world, is certain to lead to more misjudgments and misinterpretations, hence, more upsets. In turn, these will lead to more efforts to "regain" control. Since the reward system and belief system have overemphasized the rational-technical aspects of life, the tendency will be to try to control 
people to make them compatible with technological fixes; that is, through too familiar modes of manipulation, to try to fix people too. More efforts to control will lead to more alienation, frustration, hostility, dropping out, and other expressions of malaise within and outside control-seeking organizations. This will be especially so as organizations seek to control situations by restricting their responsiveness to only those people who act in ways compatible with leaderships' sense of being in control. Under these conditions value differences and response demands are likely to polarize (because they are unmet while opportunities to participate and a sense of resource availability are likely to decrease). These conditions discourage organizational or environmental learning and they lead to. overload. Over all, they lead to progressive declines in responsiveness.

Of course, not all organizations or leadership will behave this way; some see the bridge ahead to another way and some already have a foot on it. The purpose of the above exercise has been to indicate how, if organizations persist in operating according to a limitless growth world view, the consequences appear to lead to unnecessary and self-defeating limits on responsiveness. The responses of some organizations may be, indeed for some already are, in directions that facilitate more responsiveness. This facilitation may be more compatible with a world view congenial with a "steady state", "organic growth", "flow-through" society, or whatever an ecologically aware interpretive context might come to be called. Next I shall attempt to show how such an ecologically-sensitized interpretive context might help the transition to the other side.

\section{How Might a Steady-State Ethic}

\section{Reduce the Limits on Organizational Responsiveness?}

Let me not be misunderstood; the transition is certain to lead to information and decision-making overload as great as that I surmize to accompany "business as usual". Redistribution of the world's goods and services, learning how to do these things and doing all of them with an appreciation that we must reperceive our knowledge-or lack of it-will be enormously heavy burdens. There will be the strong tendencies to fall into the same traps described here earlier. We are in very deep trouble either way: if we get out at all, it may well be through some longer evolutionary transformation of society not now even imaginable. (This has happened before several times [9].) In what follows I speculate hopefully that, if an ecological paradigm were to become the dominant interpretive context, these limits to organizational responsiveness might be reduced enough to give us time to become some other sort of human condition that lives humanely and fully without dependence on the myth of limitless growth.

I take it the ecological interpretive context assumes the interdependence of all things and events netted into unnumbered consequences. It assumes that resources are limited either in their availability or by virtue of the adverse consequences to the net of life-sustaining and life-enriching processes that unavoidably result from a state of mind that uses them as if they were unlimited. It assumes that humans have wants and needs that, beyond a modest comfort level, are unmet by material goods, and that obsessive consumption of material things results from repression of human potentialities. These potentialities have been repressed in the interest of rationalizing the unlimited production of things in the service of limitless growth-which, ironically, is justified in terms of a higher standard of living.

Of special importance is the assumption that humans, to be fully human, are ineluctably interdependent. Finiteness emphasizes interdependence-or exclusion and an- 
nihilation, a "lifeboat ethic". For this paper we shall assume humans will be wise enough to realize that those who "sow the wind reap the whirlwind", at least psychologically, and that we will be lucky enough for wisdom to prevail. ${ }^{2}$

Then, in a world view built around interdependence, distinctions like I-you, we-they, subject-object, body-mind, today-tomorrow become far more problematic and tentative than they typically have been taken for in technologized societies. With this change in interpretive context comes the simultaneous appreciation of the multiple net-like connectedness of all things and circumstances and the finiteness of human abilities to understand and to control. The acceptance of the finiteness of resources, and of the earth's and people's ability to absorb the consequences of their profligate use, could release people from the thrall of equating themselves with their possessions and with the successful pursuit thereof. This would encourage a growing appreciation of the unlimited opportunities there are for people to grow from each other and from self.

What might be some consequences of this philosophy in terms of the limits of organizational responsiveness? As with the earlier speculations, I am assuming here that to a sufficient degree the view is shared by organizations and their environments. If the organization's demanders persist in the old viewpoint, it may well be impossible for any organization, no matter how enlightened and well meaning, to undertake the learning and to acknowledge its limited competence, much less to generate support for the redistribution needed to provide the human energy, health, self-respect, and opportunity to seek other means of fulfillment that do not depend on obsessive production and consumption.

Recognition of the limits of resources and of knowledge and of the necessity of interdependence would shift the content and direction of rising expectations in the direction of emphasis on improvements in access to the basics of human decency for the poor and, mostly among those more affluent, at first, anticipations of more opportunity for personal development. As the more than minimum conditions of living are met, then the search for less material forms of growth would (in this scenario) spread to all people.

There will be conflicting demands, of course. The transition period is what will preoccupy us and, during it, fears and hopes will express themselves clamorously. But to the extent that the ideas of finite resources and of interdependence prevail there may be less tendency for groups to assume they can go off and do their own thing. Thus, incentives to integrate, i.e., to share across groups, may be greater. This could make it easier for organizations to reflect in their own structure the shared relationships and values of their demanders and, thus, they might be able to respond more fully.

With the new emphases organizations could devote more time and effort to establishing effective modes of participation for the purposes of providing mutual experience that would lead to the understanding requisite for inventing more efficacious responses within the perceived availability of resources ... a perception which could be shared with and perhaps altered by the actions of the participant demanders. Ample evidence indicates that such participative approaches can result in both more responsive use of resources and in different demands on them [10]. Since participation is a means

2 If a "life boat ethic" prevails, the survivors will be too guilt ridden, too hastily and hostilely defensive of their boat and the means used to attain it, to be capable of meeting the conditions for societal learning and, thereby, for greater organizational responsiveness. 
for fostering interdependence this increased sharing of perspectives through mutual experiencing might well reduce the need to seek further resources and/or recognition through excessive autonomy. By this very circumstance the need for more centralized coordinating of resource allocations among contending and centrifugal groups could decrease. At the same time, the opportunities could increase for more decentralized self-regulating systems of goverance based on the norm of entitlement by virtue of acknowledged interdependence, of mutual responsibility. In these ways some present limits on organizational responsiveness might be reduced.

Under conditions of finiteness there would be no justification for indiscriminate proliferation of technology in the name of greater production and consumption. However, the problem would still remain of which extant and new technologies should be operated and developed to further the values and motives of an interdependent world. Recognition of our ignorance about the consequences of technological impacts would emphasize the need for a learning approach rather than an engineering approach to planning social change and providing organizational responsiveness. This would increase attention to the future as a major criterion for action in the present. This emphasis, along with other aspects about which we have been speculating, would result in heavy emphasis on goal choices but not chiefly to establish end points, targets. Rather, goal clarifying becomes a means for engendering responsibility for attending closely to where we are now as a basis for deciding where we might want to be later. Our conventional approach of settling for agreed on means, rather than seeking shared goals as the precondition for choosing means, is viable only so long as there is belief that the world can indefinitely absorb the interactive social, personal, and environmental consequences of different goals being independently pursued or met by the same means, and only so long as there is belief that means and ends are separable. Neither belief is tenable in a finite, interdependent world view. Attention to goals means attention to values and thence to feelings. So interpersonal competence would be highly rewarded in organizations emphasizing this interpretive context. With this would come the gains in organizational responsiveness that derive therefrom.

Since people would be rewarded for their interpersonal competences, it would be far easier to share the feelings and misgivings of high levels of uncertainty and, in the interest of organizational learning, to embrace errors rather than hide them.

Because the emphasis would be on learning, organizations would reward their members for sharing information internally rather than preempting it for subunit survival and aggrandizement. And, through better responsiveness, organizations would reward their demanders for also providing needed information.

In all these ways it is likely organizational behavior would become more responsive both inside and outside. Of course, overload would be great but the present sense of beleaguredness could be less. The overloaded person would not be so alienated from self or from demander, nor would the person be defending self or hiding from others recognition of finiteness of knowledge and control. Operating in a learning mode would certainly be exhausting under these conditions; but it would also be exhilerating. Most important of all, it would provide both demander and responder with the sense of community and of dignity that comes from acknowledging mutual dependence, mutual membership between humans and between humans and the cosmos. This could offer each person a vision of unlimited human possibilities undreampt of in the cramped philosophy of unlimited material growth. 


\section{References and Notes}

1. Michael, Donald N., On Learning to Plan-and Planning to Learn, Josey-Bass, San Irancisco, CA, 1973; and Michael, Donald N., The Unprepared Society, Basic Books, New York, NY, 1968.

2. See Mitroff, I. and Turoff, M., The Whys Behind the Hows, IEEE Spectrum 10 (March 1973), for a summary and application to technological assessment methods of the more detailed position set out in Churchman, C. W., The Design of Inquiring Systems, Basic Books, New York, NY, 1971.

3. The concept of "interpretive context" draws heavily on that of "appreciation" as defined and applied in Vickers, G., The Art of Judgment, Basic Books, New York, NY, 1965.

4. The critical challenge of providing experiences appropriate for the kind of understanding needed to guide this complex and turbulent world is examined in Vicker's, G., Social and Institutional Reality, (a paper to be incorporated in his forthcoming book based on his Regents' lectures delivered at the University of Calif., Berkeley, 1975.)

5. Japanese corporate practice, with its extensive participation throughout the managerial system, is instructive both for what it suggests about a radically different way of operating an organization, and for what it emphasizes regarding the centrality of cultural norms and interpretive contexts for defining competent behavior. See Johnson, R., and Ouchi, W., Made in America (Under Japanese Management), Stanford University Graduate School of Business Research Paper No. 201, Palo Alto, CA, (March 1974).

6. Meier, R., Communications Stress, Ann. Rev. Ecol. Systematics 3 (1972), and Miller, J., Information Input, Overload, and Psychopathology, Amer. J. Psych. 116. Note, especially that "information overload" is not just a quantitative matter of bits per second, so to speak. It is at least as much a product of the ambiguity, vagueness, and insufficiency of meaning that deforms rather than informs about social processes and circumstances. See Dunn, E., Social Information Processing and Statistical Systems-Change and Reform. Wiley, New York, NY, 1974, p. 20.

7. Dunn, E., op cit. and Dunn, E., Social and Economic Development: a Process of Social Learning, Johns Hopkins, Baltimore, MD, 1971, and Michael, D., op. cit.

8. Vickers, G., Ecology, Planning and the American Dream, in The Urban Condition, Duhl, L., ed., Basic Books, New York, NY, 1963.

9. Mumford, L., The Transformations of Man, Harpers, New York, NY, 1956.

10. See, for example, the literature on participative management in the U.S., Europe, Yugoslavia, and related activities in China.

Received 26 March 1976. 